\title{
Reproductive Rates in Lesser Scaup (Aythya affinis) in Southwestern Manitoba: Another Look at the Data
}

\author{
GORD HAMMELL
}

Box 37, Erickson, Manitoba R0J 0P0 Canada; email: gmhammell@gmail.com

Hammell, Gord. 2016. Reproductive rates in Lesser Scaup (Aythya affinis) in southwestern Manitoba: another look at the data. Canadian Field-Naturalist 130(2): 110-121.

Surveys indicate that Lesser Scaup (Aythya affinis) populations declined during the early 1980s and have since remained below conservation goals. Reasons suggested for the decline include chemical contamination, climate change, and reduced food resources. According to the latter theory, reproductive success of Lesser Scaup has declined because females now arrive on the breeding grounds with fewer nutrient reserves than in the past and this diminished body condition is the result of reduced food resources available at wintering and/or migration areas. To determine whether reproductive success has declined over time, I examined selected Lesser Scaup reproductive rates from 2008 to 2014 in southwestern Manitoba and compared them with those recorded before the continental population decline. Estimated productivity (age class IIa broods/pair), hatching date, Ia and IIa brood size, duckling survival rate (first sighting to age class IIa), and proportion of age class IIa broods with females in attendance were unchanged from values recorded in 1970-1972. Thus, if females are arriving on southern breeding areas with reduced body reserves, they may be recovering these losses before nesting, enabling them to attain reproductive rates similar to those in the past. In addition, these results are consistent with the hypothesis that reduced food resources at non-breeding areas could affect recruitment of southern prairie-parkland breeders to a lesser extent than northern breeders because of the longer time between arrival and egg-laying in the south.

Key Words: Lesser Scaup; Aythya affinis; Manitoba; reproductive rates

\section{Introduction}

A species' population size and distribution are determined by patterns of natality and mortality that may change over space and time. Thus, wildlife managers must understand sources of variation in these vital rates to achieve management goals, especially for a population in decline. The Lesser Scaup (Aythya affinis) is a medium-sized diving duck that breeds in the boreal forests and prairie-parklands from Alaska to northern United States (Anteau et al. 2014). Combined North American breeding populations of Lesser Scaup and the similar-looking Greater Scaup (A. marila) have declined from highs of 5-7 million birds in the 1970s to 3-4 million in the past decade (Dooley et al. 2015). The decline appears to have started in the early 1980s. Lesser Scaup constitute about $90 \%$ of the combined population and most of the decline has been attributed to this species because of widespread decline in the Canadian western boreal forest, where most Lesser Scaup breed (Afton and Anderson 2001). Lesser Scaup (but not Greater Scaup) also breed in southwestern Manitoba parkland, and a decline in the local scaup population has been noted from the early 1980 s to about 2000 when scaup numbers appear to have stabilized (Figure 1).

Several hypotheses have been offered to explain lowered scaup populations, including exposure to chemical contaminants (Custer et al. 2003; Anteau et al. 2007; DeVink et al. 2008a,b), climate changes affecting boreal forest wetlands (Drever et al. 2012), and changes in food resources in wintering and migration habitats (Afton and Anderson 2001), all of which could affect recruitment through reduced breeding propensity, clutch size, nest success, or female and duckling survival. The spring condition hypothesis ( $\mathrm{SCH}$; Afton and Anderson 2001) posits that reproductive success of scaup has declined because females now arrive on the breeding grounds with fewer nutrient reserves than they did in the past and this decline in body condition is the result of reduced food resources (quality and quantity) available at wintering, migration, or breeding areas.

Consistent with the $\mathrm{SCH}$, the body condition (spring lipid reserves) of females was lower than in the past across a wide area of the upper-midwest United States at traditional migration stopover areas (Anteau and Afton 2009a). Also, wetland quality, availability of food resources, and foraging efficiency of females were low across the same broad landscape (Anteau and Afton 2008a,b, 2009b). Similarly, on the breeding grounds, lipid reserves of females recently arrived in the southern Manitoba parkland in 2000 and 2001 were much lower than 1977-1980 values (Anteau and Afton 2004). For boreal breeding scaup, historical nutrient reserve data are sparse (body mass only; Trauger 1971) but lipid reserves of boreal females measured during 2003-2004 in northern Alberta and the Northwest Territories were much lower than historical values reported for females in northwestern Minnesota in 1986-1988 and southwestern Manitoba in 1977-1980 (Anteau and Afton 2004, 2009a; but see DeVink et al. 2008c). Furthermore,

A contribution towards the cost of this publication has been provided by the Thomas Manning Memorial Fund of the Ottawa Field-Naturalist's Club. 


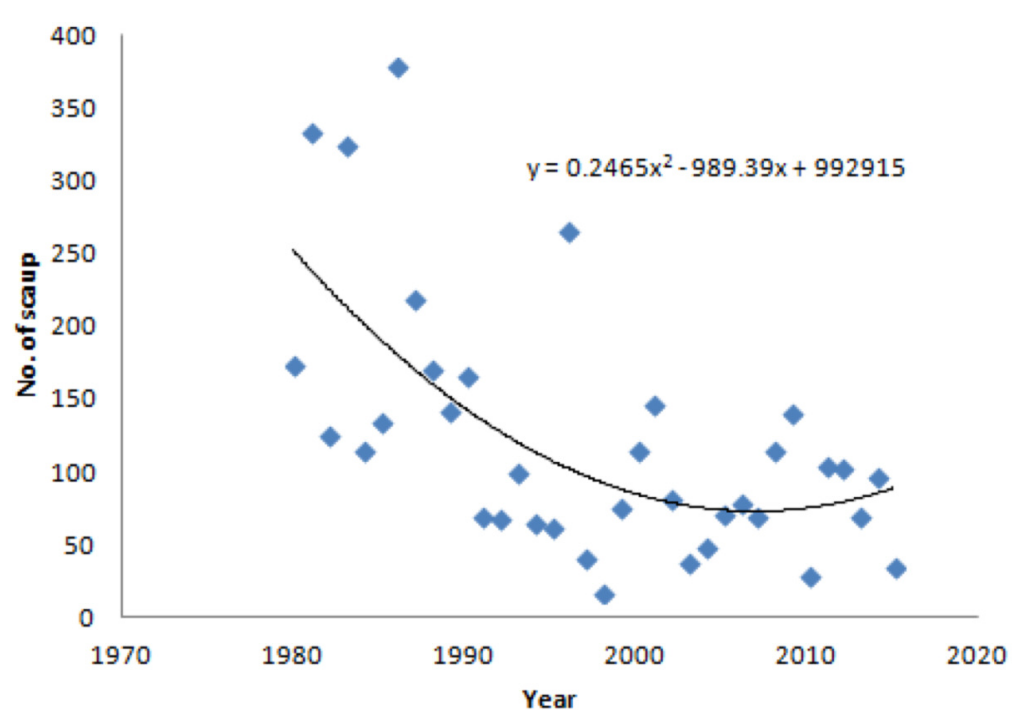

FIGURE 1. Total number of Lesser Scaup (Aythya affinis) and Greater Scaup (A. marila) from United States Fish and Wildlife Service/Canadian Wildlife Service annual waterfowl counts in the 3 segments nearest the study area near Erickson, Manitoba, 1980-2015 (stratum 40: transect 4, segment 4; transect 6, segments 3 and 4). The solid line represents a polynomial trend line. Source: Migratory Bird Data Center (n.d.).

recent studies have reported that some reproductive parameters, such as nest success, female survival, duckling and brood survival, and breeding probability, were low in boreal and parkland breeding sites, at rates that would be consistent with the SCH (Fournier and Hines 2001; Brook 2002; Koons and Rotella 2003; Walker and Lindberg 2005; Walker et al. 2005; Corcoran et al. 2007; Martin et al. 2009).

Afton and Anderson (2001) and Anteau and Afton (2009a) speculated that reduced food resources at nonbreeding areas would affect body condition and, hence, recruitment of northern boreal breeders more than southern prairie-parkland breeders because of the shorter time between arrival and egg-laying in the north. Icefree conditions occur about 1 month later at Yellowknife, Northwest Territories, a boreal breeding site, than at Erickson, Manitoba, a parkland site (Afton 1984; Brook 2002). As a result, female scaup arrive later in northern boreal areas than on southern breeding areas, but initiate egg-laying at about the same time at both latitudes (Brook 2002; Gurney et al. 2011). Resident females typically delay egg-laying by $4-6$ weeks after arrival in southern Manitoba (Afton 1984), but boreal females begin nesting shortly after arrival (Trauger 1971; Brook 2002). Such a relatively lengthy pre-laying period in the south might allow females to recoup migratory nutrient losses and better prepare for egg-laying, incubation, and brood-rearing. Therefore, in southern breeding latitudes, reproductive rates might be reduced from pre-continental population decline values, but perhaps not as much as for females breeding at higher latitudes.
However, at the Erickson breeding site, Koons and Rotella (2003) reported estimates of nest success (11\%) and duckling survival (20\%) during 1999-2000 to be low and similar to rates recorded for recent studies in boreal forest areas (Fournier and Hines 2001; Brook 2002; Walker and Lindberg 2005; Walker et al. 2005; Corcoran et al. 2007; Martin 2007). In southern Saskatchewan, in 1999-2000, Brook (2002) reported lower nest success (3\%) and duckling survival (38\% Dawson and Clark 1996) than at Yellowknife (14\% and $61 \%$, respectively). As well, Koons and Rotella's (2003) nest success and duckling survival estimates at Erickson were much lower than those recorded there before the continental population decline $(31 \%$ and $68 \%$, respectively; Afton 1984), and their female breeding season survival estimate $(73 \%)$ was lower than that reported for any northern-latitude breeding duck. In addition, clutch initiation date, which is often negatively associated with reproductive success (Dawson and Clark 2000; Esler et al. 2001; Blums et al. 2002; Brook 2002) was later than historical estimates: 24 June versus 15 June (Koons and Rotella 2003). Such low vital rates suggest that recruitment may be negatively affected in the southern breeding grounds more so than previously thought.

Field studies conducted in parkland habitat during the scaup population decline have been of short duration, e.g., 2 years (Brook 2002; Koons and Rotella 2003), and, thus, given annual variation in environmental conditions, are of limited value in determining how reproductive rates vary over time or in understanding factors affecting the rates. Accordingly, to provide 
a longer time series for reproductive success in southern parkland habitat, I collected information on Lesser Scaup from 2008 to 2014 (the recent period) and compared it with pre-decline, 1970- 1972 (the early period) data from previous research (Hammell, unpublished data, 1973). Because, at Erickson, the total number of scaup breeding pairs has declined from the early period; lower reproductive rates have been reported recently; and body condition of scaup females on arrival in spring may be lower than in the past, I predicted that recent-period reproductive rates would be lower than comparable early-period estimates.

I predicted that my current estimates of productivity and duckling survival would be lower than those recorded in the early period on the basis of Koons and Rotella's (2003) findings. I also expected mean Ia and IIa brood sizes to be smaller mainly because of lower duckling survival. I expected my recent mean hatching date (MHD) estimates to be later than those in the early period if scaup are initiating egg-laying later (Koons and Rotella 2003), but still renesting at similar rates described for the early period (Afton 1984). However, MHD might not be later (similar to the early period) or might even be earlier if scaup are initiating laying later but not renesting because of time constraints resulting from a shorter breeding season (i.e., exhibiting a truncated hatching distribution relative to that in the early period). Also, female waterfowl are usually in poor body condition at hatch, and time spent in brood care reduces time spent on self-maintenance in preparation for migration (Afton and Paulus 1992). Female scaup leave their broods for longer times as broods mature and eventually abandon them and spend more time feeding than when with broods (Afton 1993). Presum- ably, adult females can regain lost reserves more efficiently than females with broods. Therefore, if broodrearing female scaup are in poorer body condition and/ or are initiating nesting later than in historical times, the decision to abandon the brood might be made earlier, and I would expect my recent study to show lower proportion of age class IIa broods with an attending female.

\section{Study Area}

The study area is situated in the parkland pothole region of southwestern Manitoba near Erickson $\left(50^{\circ} 30^{\prime} \mathrm{N}\right.$, $\left.99^{\circ} 55^{\prime} \mathrm{W}\right)$. The topography of the area is rolling with numerous ponds and lakes. The intensively studied areas constitute a block $\left(6.8 \mathrm{~km}^{2}\right)$ and a roadside transect $(71 \mathrm{~km})$ established in 1970-1972, and the same block study area (BSA) and a different roadside transect $(21.7 \mathrm{~km}, 4.0-12.5 \mathrm{~km}$ to the southeast) established in 2009 (Figure 2). The 2009-2014 transect, which partly coincided with the earlier one, was established to increase pair and brood sample sizes as preliminary data collection in 2008 indicated that the scaup breeding population on the BSA (19-23 pairs, 1970-1972) had decreased significantly (2-5 pairs, 2008-2014; Hammell 2014). Given the study goals and resources available, this new, spatially proximate transect was logistically more feasible than the historical one. In 1970-1972, the BSA contained about 160 wetlands: 68 class 1,50 class 2,12 class 3,7 class 4 , and 23 class 5 ; size range $\leq 0.2-11.5$ ha (Stewart and Kantrud 1971). In 2008-2014, there were about 141 (loss of 2 small dugouts and 17 class $1-3$ wetlands). Relative to other agricultural areas of Manitoba, the study site has changed little in wetland area or upland use from the

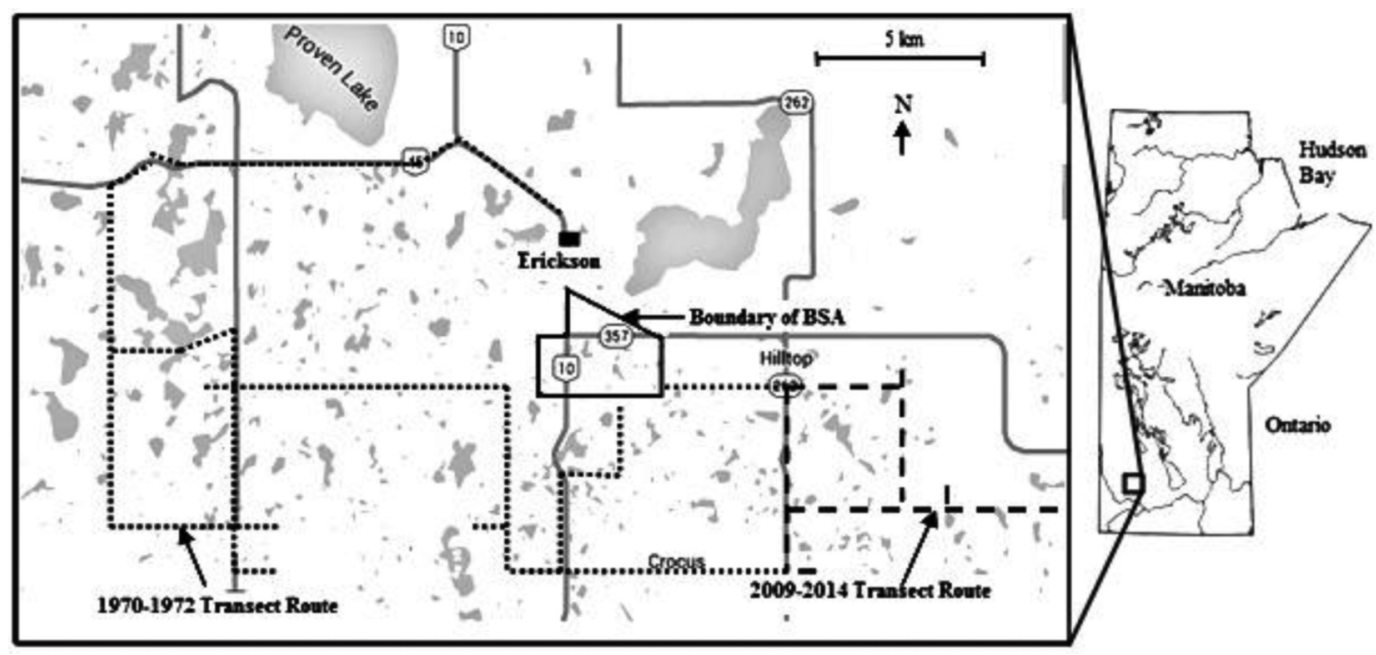

FigURE 2. Location of block study area (BSA) and 1970-1972 and 2009-2014 transects, near Erickson, Manitoba. 
early 1970s (Hammell 2014). During the record wet year, 2011, several permanent ponds (class 5) joined forming several larger wetlands (largest $21.7 \mathrm{ha}$ ). The 1970-1972 transect consisted of 56-59 semipermanent (class 4$)$ and permanent wetlands (mean $=$ 2.1 ha, range: $<0.8-8.9$ ha), selected according to size criteria, whose open water area could be viewed in entirety from a roadside vehicle. The 2009-2014 transect $\left(15.8 \mathrm{~km}^{2}\right)$ consisted of all class $2-5$ wetlands with observable water ( 32 class 2 [temporary], 56 class 3 [seasonal], 41 class 4 , and 32 class 5) within $400 \mathrm{~m}$ on either side of the road and required walking and driving to survey adequately. I chose a $400 \mathrm{~m}$ (rather than $200 \mathrm{~m}$ ) width because evidence suggests that wider transects better represent wetland density and distribution and, thus, more reliably represent breeding density of scaup and more fully accommodate larger wetlands (Austin et al. 2000). To increase sample sizes for both study periods, additional hatch date and brood size data were collected opportunistically from other wetlands near the BSA and transects. The uplands in the Erickson area are a mixture of lands sown to cereal and oilseed crops, hay, pasture, and native woodland. During 20082014, BSA and transect land use patterns were, respectively, cultivated, $39 \%$ and $18 \%$; pasture, $13 \%$ and $43 \%$; hayland, $24 \%$ and $15 \%$; wetland, $14 \%$ and $15 \%$; woodland, $6 \%$ and $5 \%$; other (yard sites, ditches, commercial, etc.), $4 \%$ and $4 \%$. One permanent small island occurred on the BSA and none on the 2009-2014 transect. The area and changes over time are described in more detail by Rogers (1964), Sunde and Barica (1975), Afton (1984), Koons and Rotella (2003), and Hammell (2014).

\section{Methods}

\section{Breeding pair surveys}

To record breeding populations of scaup on the BSA, 1 or 2 observers walked a fixed route at approximately weekly intervals from early May to late June, 19701972, and from mid-May to mid-June, 2008-2014 (56 annual surveys). Wetlands were scanned from 1 or more elevated locations between 0600 and 1400. All class 1-5 wetlands were visited. Observed pairs and single males and females on isolated ponds were added for total pair count. I used data from surveys conducted after migration but during the pre-egg-laying and earlylaying periods to avoid the bias of non-paired males being counted as representing pairs. Migration was considered over when pair numbers stabilized on the BSA. I approximated timing of egg-laying by backdating egg embryo age in nests $(n=63)$ found in 1970-1972 (Westerskov 1950) or by backdating from estimated date of earliest brood appearance (assuming egg-laying + incubation $=36$ days) in 2008-2014. I averaged the results of BSA surveys within years and used these values for comparison between 1970-1972 and 20092014.

On the 1970-1972 roadside transect, I collected data at approximately weekly intervals (about $6 \mathrm{~h}$ to com- plete) but this information was not suitable for comparisons of productivity (broods/pair) with recent data because not all ponds in a pre-determined area were observed (only selected classes 4 and 5); therefore, in 1970-1972, breeding-pair estimates were derived from BSA data only but brood data were from the BSA and transect. For breeding pair counts on the 2009-2014 roadside transect, I used criteria similar to those for the BSA. I conducted counts between 0530 and 1800 as scaup were highly visible throughout the day and previous research has shown no differences in numbers of indicated pairs for counts conducted from 0530 to 1330 (Diem and Lu 1960). From 2009-2014, I conducted 3 annual roadside surveys during late migration to early nesting (21-25 May, 31 May-4 June, 6-11 June). I walked to distant or hidden wetlands and viewed them from several locations to ensure complete coverage. For 2009 and 2010, time constraints allowed only a partial survey of this transect ( $40 \%$ of class 2 and 3 wetlands, $60 \%$ of class 4 and 5 wetlands), taking about $8 \mathrm{~h}$ to complete. For 2011-2014, I visited all wetlands with observable water (classes 2-5) within $400 \mathrm{~m}$ of the road, over 2 days $(17 \mathrm{~h}$ ). I checked class 1, tillage and class 2 wetlands with closed emergent vegetative stands while en route to other wetlands but did not visit these consistently as scaup are rarely observed on them (Hammell 1973; this study). Some wetlands were bisected by the roadside transect; thus, I recorded pairs on the entire wetland and included this total in the total transect pair count.

As the 2009 and 2010 transect pair data were incomplete, results were adjusted for biases described above to estimate the number of pairs on the entire transect for those years. Using 2011-2014 data, I developed a correction factor (CF) for each survey count using numbers of pairs observed on all wetlands and numbers observed only on wetlands that were in addition to those surveyed in 2009 and 2010:

$$
C F=\frac{P R_{\text {added }}}{P R_{\text {total }}}
$$

where, in 2011-2014, $P R_{\text {added }}$ is the number of pairs counted on wetlands that were not visited in 2009 or 2010 , and $P R_{\text {total }}$ is the total number of pairs counted on all wetlands. This factor is the proportion of the count on missed wetlands and was determined within each year for those counts considered post-migration and these values were averaged. The average $\left(\mathrm{CF}_{\text {average }}\right)$ of the yearly count averages for 2011-2014 was applied to average counts for 2009 and 2010, e.g.,

$$
\text { Estimated total pairs all ponds }(2009)=\frac{\text { Average pairs recorded }(2009)}{\left[1.00-C F_{\text {average }}\right]}
$$

This analysis indicated that the mean number of scaup pairs recorded in 2009 and 2010 on the partly surveyed transect represented about $70 \%$ of the total number of pairs on the entire transect and this adjustment was applied to the 2009 and 2010 raw data as above. Yearly 
productivity estimates for the BSA and transect correlated positively in the recent period and means did not differ significantly (unpublished data); thus, estimated pairs and broods on the BSA were added to those on the roadside transect and this total represented the pair and brood estimate on the entire $22.6 \mathrm{~km}^{2}$ study area.

\section{Brood surveys}

Broods of scaup are relatively easily found, as they usually swim to open areas in the centre of the pond when disturbed (Hammell 1973; Anteau et al. 2014). I described a brood as (a) a female with up to 12 ducklings or (b) as 2-12 isolated ducklings with no female and whose age did not correspond with that of other nearby broods. Larger groups (13-24 ducklings) were considered 2 broods. Broods were observed on wetlands on the BSA, roadside transects and nearby areas. I recorded presence or absence of an adult female and number and age of ducklings, and used information about brood age, size, and location to avoid duplication in counts. Occasionally, scaup broods contained ducklings of other waterfowl species, usually Redhead (Aythya americana) and these ducklings were removed from the recorded scaup brood size. I estimated brood ages based on juvenile plumage characteristics (Gallop and Marshall 1954). For each brood, a hatching date was estimated by backdating from several brood observation dates. During 1970-1972, some females were marked with a coded plastic nasal saddle, so that broods were more readily identified (Sugden and Poston 1968). Brood surveys began during the first week of July and, because scaup females usually move their broods from smaller to larger (usually class 5) wetlands as they mature (Hammell 1973; Corcoran et al. 2007), surveys were conducted mostly on class 4 and 5 wetlands until broods reached age class IIa (21-28 days of age). Greatest duckling losses and most brood movement occur before ducklings reach age class IIa (Hammell 1973; Afton 1983; Dawson and Clark 1996; Brook 2002; Corcoran et al. 2007). Also, most brood-rearing females spend increasing amounts of time away from their broods after they reach age class IIa, and at that point ducklings often form groups on lakes making it difficult to distinguish individual broods (personal observations; Hines 1977; Afton 1984). Thus, class IIa broods are relatively stable in size and location, represent a good index of juveniles fledged, and have been used similarly by other authors (Afton 1984; Koons and Rotella 2003).

Brood search effort on the BSA and transects averaged about 7 visits/wetland annually (1970-1972: mean 7.0 , range $5-9$, no. wetlands $73-76 ; 2008-2014$ : mean 7.2 , range 5.5-9, no. wetlands 35-54). I assumed that the number of broods that left the study areas was equal to the number that arrived. Because broods move freely over the entire area of a lake (unpublished data), placing a brood "in" or "out" of the transect was difficult when the transect line bisected a lake. Thus, I counted all broods on bisected lakes and assumed that these broods resulted from the total pair count for that lake. Occasionally, broods disappeared between counts and may have moved to a nearby wetland or suffered total brood loss; the extent of such possible losses was unknown. Brood surveys on the transect were incomplete in 2009 and 2010 (3 potential brood wetlands unobserved out of 47); thus, a correction factor was applied to these data similar to that for pairs. This analysis resulted in 1 brood each being added to 2009 and 2010 total estimates.

\section{Data analysis}

Recent-period estimates of breeding pairs and broods allowed for comparisons of productivity (IIa broods/ pair) and Ia (1-6 day old) and IIa (21-28 day old) brood size with early-period estimates. Because I was interested in changes between periods rather than individual years, I pooled brood size and hatching date data across years within each period. Yearly productivity estimates and brood size data for each period were tested for differences using Wilcoxon rank-sum test (data analysis using Excel, Microsoft, Redmond, Washington, USA).

Changing mean clutch size could confound brood size analysis, but I assumed no change over time based on recent research findings at Erickson: mean clutch size (1999-2000) was unchanged from historical times (Koons and Rotella 2003). I determined MHD for each period (all years combined) and looked for hatching date differences using the Kruskal-Wallis test (McDonald 2014). Similar MHD can result from different hatching distributions; thus, to look for change in hatching distribution (using analytic methods of previous authors; Rogers 1962; Hines 1977), hatching dates were assigned to weekly hatching periods in each era and compared using a Kolmogorov-Smirnov test (Holliday 2012). I tested early and recent data with non-parametric Wilcoxon and Kruskal-Wallis tests because the distribution of variables was unknown, sample sizes were small, or both. Because unpublished analysis of data distributions for the early versus recent periods (hatch date, brood size) indicated that they were similarly shaped and reasonably symmetric, I interpreted results as being tests of differences in mean values.

Mean estimates and confidence intervals for duckling daily survival rate (DSR) for the exposure period between first sighting and age class IIa (21-28 days) were calculated for early and recent periods using procedures outlined by Mayfield (1975) and Johnson (1979), and 95\% confidence intervals for DSRs were examined for overlap to test for significant differences.

Amalgamated broods ( 0 or more females with $>12$ ducklings) were seen most years and were not excluded from the data set, as these broods and single broods have similar duckling survival (Afton 1993). However, I removed data for some or all of these broods on multibrood lakes if I was unable to accurately determine age and duckling number because of brood mixing and duckling exchange. Also, to provide an alternative measure of duckling survival, I selected broods continuously 
observed from age class Ia to IIa, and, for both time periods, calculated the proportion of ducklings lost. I used Fisher's exact test (McDonald 2009) to test for differences between time periods in number of ducklings lost.

Similarly, I determined the proportion of age class IIa broods with an attending female (BWF; all years combined) for early and recent periods and tested for differences with a Fisher's exact test. I excluded broods first seen without a female and broods sighted only once. When a brood female or duckling disappeared, I assumed this occurred at the mid-point of the observation interval. All statistical tests were considered significant at the $P \leq 0.05$ level.

\section{Results}

\section{Productivity}

During the early period (BSA only, $6.8 \mathrm{~km}^{2}$ ) and the recent period (BSA+ transect, $22.6 \mathrm{~km}^{2}$ ) total pairs for all years were estimated at 64 and 245, respectively, and total IIa broods recorded were 15 and 75, respectively (Table 1). Brood production was higher in years with relatively stable or rising summer water-levels (1971, 2010-2011, and 2013-2014) and decreased in years with declining summer water-levels $(1970,1972$, and 2009) or dry emergent conditions (2012). Yearly productivity (broods/pair) values for early and recent periods were not significantly different $(P=0.64$; Table $1)$. The range of recorded broods/pair values over both dry and wet summer conditions was similar for both the early (range 0.09-0.47) and recent period (range 0.060.48).

\section{Mean hatch date and hatching chronology}

MHD for the early period (30 July \pm 1 day [day $210.9 \pm 0.96 \mathrm{SE}, n=118])$ and for the recent period (28 July \pm 0.7 day [day 209.2 $\pm 0.70 \mathrm{SE}, n=216]$ ) were similar $(P=0.16$; Table 2$)$.

Likewise, the distribution of broods hatching at weekly intervals did not differ between periods $(P=$ 0.98 ; Figure 3).

\section{Brood size, duckling survival and proportion IIa broods with attending female}

Mean sizes of Ia and IIa broods were similar for both periods (Ia [early]: mean $6.7 \pm 0.3 \mathrm{SE}, n=78$; Ia [recent]: mean $6.6 \pm 0.3 \mathrm{SE}, n=113, P=0.76$; IIa [early]: mean $6.0 \pm 0.3 \mathrm{SE}, n=51$; IIa [recent]: mean $6.0 \pm 0.3 \mathrm{SE}, n=126, P=0.99)$. The $95 \%$ confidence interval for the early-period DSR estimate overlapped that for the recent period; thus, DSR for the 2 periods was not different (Table 3). Duckling survival expressed as the percentage of lost age class Ia ducklings to age class IIa for the early and recent periods $(10.5 \%, n=$ 200 and $12.6 \%, n=461$, respectively) was not significantly different $(P=0.52)$. The proportion BWF (all years) for the early period $(0.77, n=53)$ was not significantly different from that of the recent period $(0.86$, $n=135, P=0.19$ ).

TABLE 1. Lesser Scaup (Aythya affinis) productivity in 1970 1972 and 2009-2014, near Erickson, Manitoba.

\begin{tabular}{lccc}
\hline \hline Year & $\begin{array}{c}\text { Estimated } \\
\text { pairs }\end{array}$ & $\begin{array}{c}\text { IIa } \\
\text { broods }\end{array}$ & $\begin{array}{c}\text { Broods/ } \\
\text { pair }\end{array}$ \\
\hline $\begin{array}{l}\text { Early period } \\
\quad\end{array}$ & & & \\
1970 & 22 & 4 & 0.18 \\
1971 & 19 & 9 & 0.47 \\
1972 & 23 & 2 & 0.09 \\
Total or mean & 64 & 15 & $0.23^{*}$ \\
Recent period & & & \\
2009 & 45 & 9 & 0.21 \\
2010 & 38 & 14 & 0.37 \\
2011 & 44 & 17 & 0.40 \\
2012 & 34 & 2 & 0.06 \\
2013 & 44 & 14 & 0.32 \\
2014 & 40 & 19 & 0.48 \\
Total or mean & 245 & 75 & $0.31^{*}$ \\
\hline \hline
\end{tabular}

*Weighted means, adjusted for annual variation in numbers.

TABLE 2. Mean hatching dates for Lesser Scaup (Aythya affinis) during 1970-1972 and 2008-2014, near Erickson, Manitoba.

\begin{tabular}{lccc}
\hline \hline Year & Mean hatch date \pm SE* & No. broods & Range (days) \\
\hline Early period & $212.5 \pm 1.3$ & 43 & $193-227(34)$ \\
1970 & $212.1 \pm 1.6$ & 53 & $191-234(43)$ \\
1971 & $204.8 \pm 2.0$ & 22 & $189-224(35)$ \\
1972 & $210.9 \pm 1.0$ & 118 & $189-234(45)$ \\
Total or mean $\dagger$ & & & \\
Recent period & $215.4 \pm 1.9$ & 18 & $198-231(33)$ \\
2008 & $210.0 \pm 2.5$ & 22 & $188-229(41)$ \\
2009 & $211.5 \pm 1.8$ & 32 & $192-228(36)$ \\
2010 & $204.8 \pm 1.4$ & 46 & $188-231(43)$ \\
2011 & $204.9 \pm 1.5$ & 13 & $194-215(21)$ \\
2012 & $208.8 \pm 1.6$ & 37 & $191-232(41)$ \\
2013 & $210.7 \pm 1.5$ & 216 & $187-231(44)$ \\
2014 & $209.2 \pm 0.7$ & $187-232(45)$ \\
Total or mean $\dagger$ & &
\end{tabular}

*Days from 1 January; $\mathrm{SE}=$ standard error.

$\dagger$ Weighted means, adjusted for annual variation in numbers. 


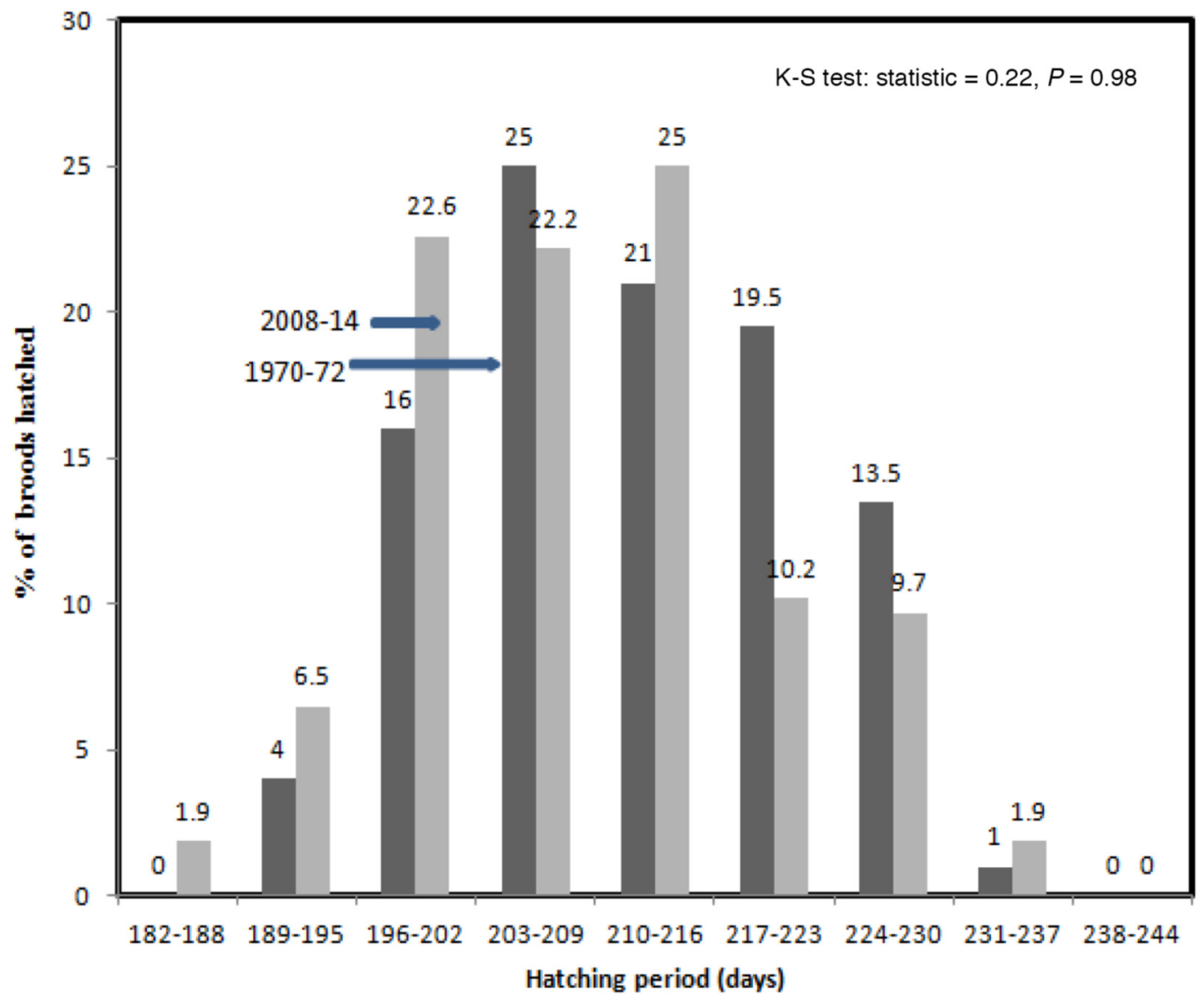

FIGURE 3. Hatching distribution for Lesser Scaup (Aythya affinis) near Erickson, Manitoba. Days are counted from 1 January. For 1970-1972, $n=118$ (dark grey bars); for 2008-2014, $n=216$ (light grey bars). K-S test = Kolmogorov-Smirnov test.

TABLE 3. Number of broods, exposure, losses, and daily survival rates for Lesser Scaup (Aythya affinis) ducklings from first sighting to age class IIa 1970-1972 and 2008-2014 near Erickson, Manitoba.

\begin{tabular}{|c|c|c|c|c|c|c|c|c|}
\hline Year & $\begin{array}{l}\text { No. } \\
\text { broods }\end{array}$ & $\begin{array}{c}\text { No. } \\
\text { observations }\end{array}$ & $\begin{array}{c}\text { No. } \\
\text { intervals }\end{array}$ & $\begin{array}{c}\text { Mean } \\
\text { interval } \\
\text { length } \\
\text { (days) }\end{array}$ & $\begin{array}{c}\text { Total } \\
\text { exposure } \\
\text { (duckling- } \\
\text { days) }\end{array}$ & $\begin{array}{c}\text { Total } \\
\text { losses }\end{array}$ & $\begin{array}{l}\text { Daily } \\
\text { survival } \\
\text { rate }\end{array}$ & $95 \% \mathrm{CI}$ \\
\hline \multicolumn{9}{|l|}{ Early period } \\
\hline 1970 & 16 & 58 & 43 & $6.9(6.0-8.0)$ & 1705.0 & 5 & 0.99707 & 0.99475-0.99939 \\
\hline 1971 & 31 & 130 & 104 & $6.5(4.0-10.5)$ & 3824.5 & 17 & 0.99566 & $0.99458-0.99674$ \\
\hline 1972 & 10 & 39 & 29 & $7.0(3.0-15.0)$ & 1127.0 & 5 & 0.99556 & $0.99160-0.99952$ \\
\hline Total or mean & 57 & 227 & 176 & $6.8(3.0-15.0)$ & 6656.5 & 27 & 0.99594 & $0.99438-0.99750$ \\
\hline \multicolumn{9}{|l|}{ Recent period } \\
\hline 2008 & 10 & 23 & 18 & $8.5(1.0-20.0)$ & 1079.0 & 4 & 0.99629 & 0.99997-0.99261 \\
\hline 2009 & 15 & 60 & 47 & $6.2(1.0-15.0)$ & 1525.5 & 18 & 0.98820 & $0.98268-0.99372$ \\
\hline 2010 & 25 & 98 & 72 & $7.3(1.0-20.0)$ & 2647.0 & 13 & 0.99509 & 0.99235-0.99779 \\
\hline 2011 & 31 & 121 & 90 & $7.0(0.5-24.0)$ & 3751.0 & 20 & 0.99467 & $0.99229-0.99705$ \\
\hline 2012 & 12 & 39 & 24 & $7.8(3.0-10.0)$ & 1579.0 & 12 & 0.99240 & 0.98803-0.99677 \\
\hline 2013 & 28 & 93 & 70 & $6.0(1.0-19.0)$ & 2438.0 & 19 & 0.99221 & $0.98865-0.99577$ \\
\hline 2014 & 31 & 91 & 62 & $6.5(1.0-13.0)$ & 2522.0 & 22 & 0.99128 & $0.98758-0.99498$ \\
\hline Total or mean & 152 & 525 & 383 & $6.9(0.5-24.0)$ & 15541.5 & 108 & 0.99305 & 0.99151-0.99459 \\
\hline
\end{tabular}




\section{Discussion}

Contrary to my expectations, the reproductive parameters that I examined (i.e., IIa broods/pair, hatching dates, hatching chronology, Ia and IIa brood size, duckling DSR, and proportion BWF) have not changed between 1970-1972 and the present. If changes in natality have occurred, they are not discernible in these data. Small sample sizes may have limited my ability to find differences.

\section{Productivity}

For the early and recent periods, mean productivity was similar and yearly productivity was high $(>0.3$ broods/pair) in wet years with stable water levels and much reduced $(<0.1$ broods/pair) in dry years when water levels were low or rapidly declining. My estimate of mean productivity ( 0.31 broods/pair) and productivity range for recent years was also similar to values reported at Erickson in 1977-1980 (Afton 1984). Afton's productivity estimates (nest success, assumed to be equivalent to broods/pair at hatch) ranged from 0.18 during a dry year to 0.40 during the wettest year. In contrast, using Koons' (2001; personal communication) recorded pair and brood data on his $25.8 \mathrm{~km}^{2}$ Erickson study area, I calculated a broods/pair estimate of 0.09 ( $n=43$ pairs) and $0.17(n=30$ pairs) in 1999 and 2000 respectively, despite the wet habitat conditions. Neither of these studies published total brood loss or IIa broods/ pair values comparable to my study. Published estimates of total brood loss for scaup are few and limited to boreal scaup, but losses are high (Walker and Lindberg 2005; Corcoran et al. 2007).

Undoubtedly, some total brood loss is occurring at Erickson and, therefore, nest success may be higher than my IIa broods/pair values suggest.

Several potential biases may have affected my productivity estimates. In North Dakota, USA, Pagano and Arnold (2007) found that replicated single-observer counts of scaup pairs could underestimate breeding pairs by about $11 \%$ and thus, my broods/pair counts could be biased high. In addition, I cannot verify my assumption that no net brood movement occurred on and off the study areas. Nonetheless, my early and recent estimates are comparable as similar detection biases could apply to pair and brood counts. In addition, my recent transect may differ from the BSA in habitat quality for female and brood success and all recent reproductive estimates could be biased. However, I believe that habitat quality is similar across the study areas because preliminary analysis showed similar broods/pair trends over time for the BSA and recent transect and topography, soils, wetland type, predator community, and agricultural practices appear similar. Age structure of the female population can affect productivity and any change in this structure might bias results when comparing time periods. Declining age ratios in the scaup harvest suggest lower recruitment (Afton and Anderson 2001) and possibly a recent breeding population included a higher proportion of older, more experienced adults.
Older females have better reproductive performance (Afton 1984) and this might account for the higher productivity I recorded in recent years. I have no data to assess this, but during 1999-2000, Koons and Rotella (2003), working with marked females, found little change (except for 3 year olds) from historical age structure in the Erickson population. Change in breeding propensity could affect my broods/pair ratios if resident breeding females fail to breed and do not settle on the study area, but this potentially important matter is beyond the scope of this study and I have assumed no change in breeding propensity over time. I suggest that future researchers address these possible biases for scaup broods/pair estimates in parkland and boreal habitat to assess the utility of estimating yearly production by this relatively inexpensive method.

Koons and Rotella (2003) reported low nesting success rates at Erickson in 1999 and 2000 (10.8\% and $12.1 \%$, respectively), both years with wet conditions. These values are much lower than Afton's (1984) predecline estimates and my productivity estimates. Koons and Rotella attached radio transmitters to females and these devices have been shown to negatively affect some reproductive parameters (Paquette et al. 1997; Guyn and Clark 1999; Barron et al. 2010; Arnold and Howeter 2012; Bloom et al. 2012; but see Pietz et al. 1995); however, Koons and Rotella found no evidence of bias in nest survival estimates (unpublished analysis). Brook (2002) reported mean nest success for 19992000 at St. Denis, Saskatchewan, to be very low (3\% for mainland nests; $95 \% \mathrm{CI}=0.004-0.120, n=18$ ), but increasing drought conditions may have negatively influenced these results (R. Clark, personal communication). Again, my productivity estimates (IIa broods/ pair) result from different methods but it is difficult to imagine how such low nest success reported by these authors could translate into the numbers of broods recorded on my study areas. These contrasting results may simply reflect a high degree of spatial-temporal variation in scaup reproductive success.

\section{Mean hatch date and hatching chronology}

I found similar MHD and hatching chronology in the early and recent periods. Neither prediction that hatching dates would be later because of later mean nest initiation date (9 days, Koons and Rotella 2003) nor that they would be earlier if scaup were no longer renesting was supported by my data. I interpret similar MHD and hatching chronology as resulting from no or little change in pattern of nest initiation from the predecline period because (1) estimated first nest initiation dates (by backdating first recorded brood dates by 36 days to account for egg-laying and incubation) during this study (mean day 156, range $151-168, n=7$ years) were similar to historical estimates (mean day 155, range 153-157, $n=3$ [Hammell 1973]; mean day 155, range 152-162, $n=4$ [Afton 1984]) and (2) the appearance of late-hatching broods in both periods ( $>$ day 224 , a hatching period beyond the combined laying plus 
incubation span of Afton's [1984] latest recorded initial nest) could represent renesting.

\section{Brood size and duckling survival}

Also contrary to expectations, I found no difference in brood size, DSR, or percentage duckling loss estimates between pre-decline and recent periods, suggesting no change in duckling survival after first sighting to age class IIa. In contrast, Koons and Rotella (2003) found a marked decline in duckling survival from the 1970s to 2000; their estimate of duckling survival (20\%) from hatch to age class IIa at Erickson was less than a third of Afton's (1984) pre-decline estimated mean (68\%) for 1977-1980. Because my duckling loss analysis does not include the earliest days of the brood period (age at first sighting: early period, mean 5.7 days, $n=78$; recent period, mean 6.9 days, $n=173 ; P=0.11$, no significant difference at $P \leq 0.05$ based on MannWhitney $U$ test), a period when duckling loss can be high (Hammell 1973; Afton 1984; Koons 2001; Corcoran et al. 2007), I could be missing an increase in early total brood mortality, which would not necessarily alter my brood size or DSR estimates but that would be reflected in Afton's (1984) and Koons and Rotella's (2003) hatch to age class IIa results. Similarly, a change in total brood loss occurring later in the brood period might not be evident from my data, as DSR and brood size were calculated from broods that were present on the wetlands and I made no assumptions about the fate of broods that disappeared. However, such change in total brood loss seems unlikely because age class Ia brood sizes are unchanged between periods (no increase in small broods); no significant change was observed in the proportion of broods that disappeared (moved or suffered total loss) after having been first observed (ear- ly period: $0.29, n=77$; recent period: $0.19, n=162$; $P=0.13$, Fisher's exact test; McDonald 2009); and a marked increase in total brood loss in recent times would imply unreasonably high nest success. I conclude that it is most likely that duckling survival is unchanged between early and recent periods.

\section{Proportion IIa broods with attending female}

The proportion of BWF is determined by both the degree of female reproductive investment and mortality during the brood season, and by timing of hatch (Gehrman 1951; personal observations). Females presumably balance investment in the brood with investment in themselves (e.g., regained body reserves). My results show that the proportion of BWF has not changed between periods, and assuming similar female mortality and hatching chronology for both periods, suggest that females are not abandoning broods earlier than in the past. This result is contrary to my prediction that females might abandon broods earlier in response to later nest initiation and/ or reduced body condition (Koons and Rotella 2003; Anteau and Afton 2004).

However, female brood season mortality may not be similar between study periods so I advise caution when interpreting these data. Nonetheless, this result is consistent with my other findings that reproductive parameters examined here have not changed over time.

Why, then, would scaup breeding pair numbers at Erickson have declined from the 1970 s to the present (Koons and Rotella 2003; Hammell 2014) if, as my results suggest, reproductive success has not declined? There are 19 years of nest or female success data available for Erickson, encompassing wet and dry years (Figure 4). Although these estimates may not be exactly comparable because of different methods used, they

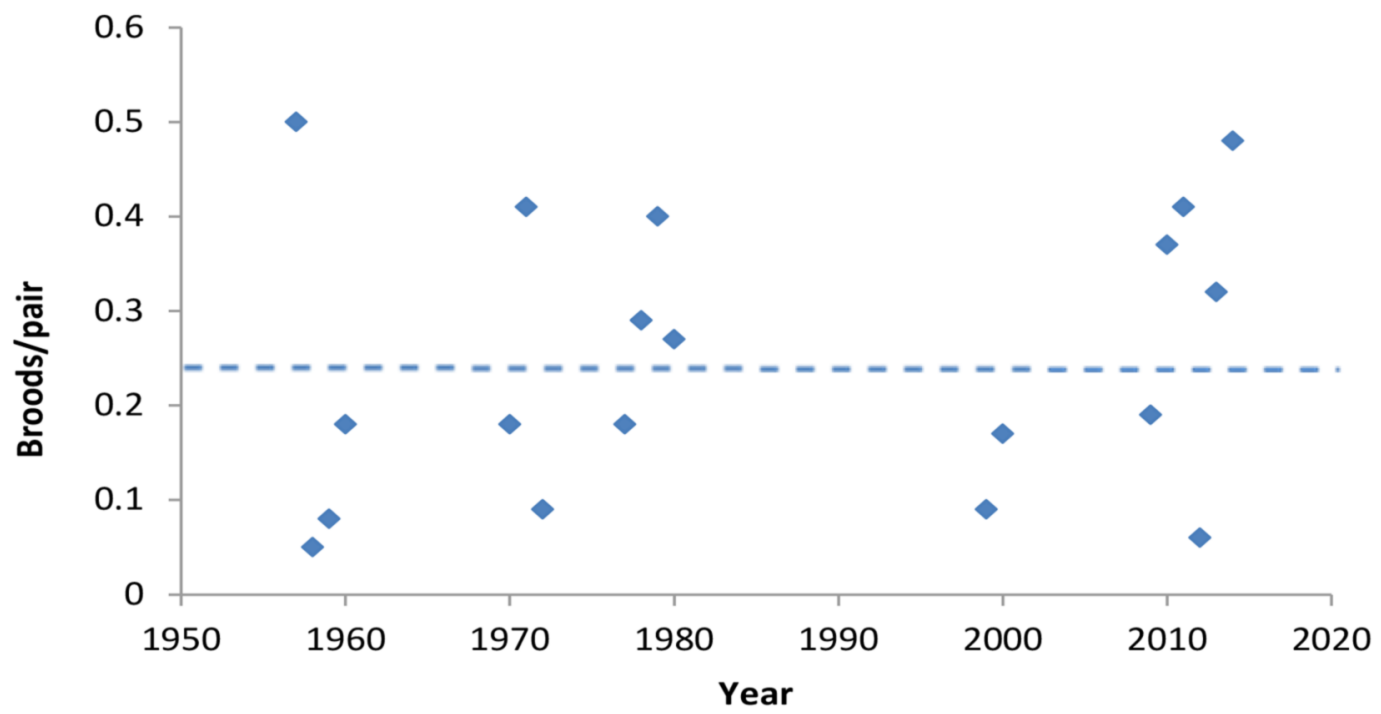

FIGURE 4. Estimates of productivity of Lesser Scaup (Aythya affinis) near Erickson, Manitoba, presented in or calculated from: 1957-1960 (Rogers 1964); 1970-1972 and 2009-2014 (this study); 1977-1980 (Afton 1984); 1999-2000 (Koons 2001). Dotted line represents productivity necessary to maintain the population. 
do show a great degree of annual variation even within studies and suggest that in the past 58 years scaup experienced "good" and "bad" production years. Using published estimates of scaup vital rates in prairie-parkland habitats (annual female survival [breeding season survival $\times$ non-breeding season survival] 0.61 ; juvenile survival rate [fledging to following breeding season] 0.55; sex ratio of juveniles 50:50; mean IIa brood size 6; Koons et al. 2006; this study), I calculated a crude productivity rate (IIa broods/pair) necessary to maintain a stable population at Erickson. I assumed that all surviving adult and juvenile females returned to Erickson the following year and that immigration was minimal, a reasonable assumption as scaup are known to exhibit a high degree of philopatry (Afton 1984). I also assumed that duckling mortality from age class IIa to fledging was nil, although some mortality likely does occur. Starting with a hypothetical 100 pairs in the spring of year $y$, annual female survival + juvenile female recruitment and survival must equal 100 at year $y+1$ for a stable population. Therefore, 61 adult females $+[($ productivity $\times 100) \times(6 \times 0.5) \times 0.55]=100$. Imposing this productivity value (calculated at about 0.24 ) on Figure 4, the frequencies of years above and below the putative maintenance line are similar and, consequently, scaup may have difficulty increasing populations over time. Indeed, a prolonged period of dry years occurred during the late 1980s to mid-1990s, when mean numbers of ponds counted on both segments 3 and 4, transect 6 near Erickson (1987-1995) were below the 1955-2014 segment means (unpublished analysis). Juvenile recruitment and breeding propensity is low during dry years (Rogers 1964; Hammell 1973; Afton 1984; this study), and, during these years, scaup might have suffered repeated annual breeding population loss. Given a continuation of historical fluctuating habitat conditions where gains in "good" years might be negated by losses in "bad" years, there may have existed little capacity for scaup to recuperate these losses following the dry period, and the population has remained low. In addition, change in survival or carrying capacity away from Erickson may have reduced the density of settling pairs.

\section{Conclusion}

My results do not support the hypothesis that Lesser Scaup reproductive success has decreased since the 1970s in the Erickson parklands. Although causal mechanisms responsible for reduced continental populations are, as yet, unresolved, my results are consistent with the hypothesis that recruitment of southern breeders is not much affected. If scaup females are arriving on the Erickson breeding grounds in poorer body condition than during the 1970s (Anteau and Afton 2004), they may be replenishing reserves during the 4-6 week prelaying period (Afton 1984) and entering the laying and incubation periods with sufficient reserves to reproduce at levels similar to historical values. Captive female scaup have been shown to completely recover from a loss of $11 \%$ body mass in only 4 days, and, during migration, some wild-living scaup could increase body mass by about $60 \mathrm{~g}$ /day under ideal foraging conditions where abundant natural foods were supplemented by corn (Martin 2007; Anteau and Afton 2008c). In addition, at a high-elevation southern breeding site in Montana, USA, during the lengthy pre-nesting period, a female of average structural size was able to increase her body condition by $2.2 \mathrm{~g} /$ day (wet weight) supplementing endogenous reserves (lipids and protein) with nutrients from local dietary sources (Cutting et al. 2011, 2014; Warren et al. 2013). Together, these results suggest that mass loss can be reversed if food supplies are adequate. In contrast, boreal breeding scaup undergo a much longer migration and may arrive at northern breeding areas with reduced reserves. On arrival, they do not have a long pre-laying period in which to regain reserves (Trauger 1971; Brook 2002) and, consequently, reproductive success may be suffering (Brook 2002; Walker et al. 2005; Corcoran et al. 2007). In fact, Afton and Anderson (2001) reported that the steepest continental scaup population declines occurred in the boreal region.

This study and that of Koons and Rotella (2003) used different methods which confound direct comparisons. A repeat of Afton's (1984) pre-decline study, using his methods, would provide additional data. Also, it would be valuable to see if the results of this study hold at other southern breeding areas, by undertaking comparative studies; historical studies exist from southern Saskatchewan and Alberta (Keith 1961; Smith 1971; Hines 1977).

\section{Acknowledgements}

Members of my University of Guelph committee, Drs. E. D. Bailey, R. J. Brooks, D. H. Pengelly, and R. E. Walker offered guidance and advice and their assistance during my student years was much appreciated. I thank the landowners and others around Erickson for their hospitality and permission to access their lands. I also thank those who provided help in the field, especially G. Curry, R. Beaver, J. Jefferson and H. Pengelly. Funds for the 1970s study were provided by the National Research Council of Canada, Delta Waterfowl Research Station, University of Guelph, and Canadian National Sportsmen's Show.

I acknowledge the recent help of I. Glass (Ducks Unlimited Canada) for library support. B. McLavy, S. Hammell, and K. Hammell helped with tables and figures. Special thanks to L. Armstrong (Ducks Unlimited Canada) for her patience and aid with data analysis. R. Clark (Canadian Wildlife Service), 2 anonymous reviewers, and Canadian Field-Naturalist editors provided helpful comments to improve earlier drafts of this manuscript. Most important, I thank Marg for her support. 


\section{Literature Cited}

Afton, A. D. 1983. Male and female strategies for reproduction in lesser scaup. Ph.D. thesis, University of North Dakota, Grand Forks, North Dakota, USA.

Afton, A. D. 1984. Influence of age and time on reproductive performance of female lesser scaup. Auk 101: 255-265.

Afton, A. D. 1993. Post-hatch brood amalgamation in lesser scaup: female behavior and return rates, and duckling survival. Prairie Naturalist 25: 227-235.

Afton, A. D., and M. G. Anderson. 2001. Declining scaup populations: a retrospective analysis of long-term population and harvest survey data. Journal of Wildlife Management 65: 781-796.

Afton, A. D., and S. L. Paulus. 1992. Incubation and brood care. Pages 62-108 in Ecology and Management of Breeding Waterfowl. Edited by B. D. J. Batt, A. D. Afton, M. G. Anderson, C. D. Ankney, D. H. Johnson, J. A. Kadlec, and G. L. Krapu. University of Minnesota Press, Minneapolis, Minnesota, USA.

Anteau, M. J., and A. D. Afton. 2004. Nutrient reserves of lesser scaup during spring migration in the Mississippi Flyway: a test of the spring condition hypothesis. Auk 121: 917-929.

Anteau, M. J., and A. D. Afton. 2008a. Amphipod densities and indices of wetland quality across the upper midwest, USA. Wetlands 28: 184-196.

Anteau, M. J., and A. D. Afton. 2008b. Diets of lesser scaup during spring migration throughout the upper midwest are consistent with the spring condition hypothesis. Waterbirds 31: 97-106.

Anteau, M. J., and A. D. Afton. 2009a. Lipid reserves of lesser scaup (Aythya affinis) migrating across a large landscape are consistent with the "spring condition" hypothesis. Auk 126: 873-883.

Anteau, M. J., and A. D. Afton. 2009b. Wetland use and feeding by lesser scaup during spring migration across the upper midwest, USA. Wetlands 29: 704-712.

Anteau, M. J., A. D. Afton, C. M. Custer, and T. W. Custer. 2007. Relationships of cadmium, mercury, and selenium with nutrient reserves of female lesser scaup (Aythya affinis) during winter and spring migration. Environmental Toxicology and Chemistry 26: 515-520.

Anteau, M. J., J-M. DeVink, D. N. Koons, J. E. Austin, C. M. Custer, and A. D. Afton. 2014. Lesser Scaup (Aythya affinis). In The Birds of North America Online. Edited by A. Poole. Cornell Lab of Ornithology, Ithaca, New York, USA. Accessed 5 December 2015. http://bna.birds.cornell .edu/bna/species $/ 338$.

Arnold, T. W., and D. W. Howeter. 2012. Effects of radiotransmitters and breeding effort on harvest and survival rates of female mallards. Wildlife Society Bulletin 36: 286290.

Austin, J. E., H. T. Sklebar, G. R. Guntenspergen, and T. K. Buhl. 2000. Effects of roadside transect width on waterfowl and wetland estimates. Wetlands 20: 660-670.

Barron, D. G., J. D. Brawn, and P. J. Weatherhead. 2010. Meta-analysis of transmitter effects on avian behaviour and ecology. Methods in Ecology and Evolution 1: 180-187.

Bloom, P. M., D. W. Howerter, J. H. Devries, L. M. Armstrong, and R. G. Clark. 2012. Radiomarking broodrearing mallard females: implications for juvenile survival. Wildlife Society Bulletin 36: 582-586.

Blums, P., R. G. Clark, and A. Mednis. 2002. Patterns of reproductive effort and success in birds: path analyses of long-term data from European ducks. Journal of Animal Ecology 71: 280-295.

Brook, R. W. 2002. Breeding ecology and local population dynamics of lesser scaup (Aythya affinis) in boreal forest of western Canada. M.Sc. thesis, University of Saskatchewan, Saskatoon, Saskatchewan, Canada.

Corcoran, R. M., J. R. Lovvorn, M. R. Bertram, and M. T. Vivion. 2007. Lesser scaup nest success and duckling survival on the Yukon Flats, Alaska. Journal of Wildlife Management 71: 127-134.

Custer, C. M., T. W. Custer, M. J. Anteau, A. D. Afton, and D. E. Wooton. 2003. Trace elements in Lesser Scaup (Aythya affinis) from the Mississippi flyway. Ecotoxicology 12: $47-54$.

Cutting, K. A., K. A. Hobson, J. J. Rotella, J. M. Warren, S. E. Wainwright-de la Cruz, and J. Y. Takekawa. 2011. Endogenous contributions to egg protein formation in lesser scaup (Aythya affinis). Journal of Avian Biology. 42: 505-513.

Cutting, K. A., K. A. Hobson, J. J. Rotella, J. M. Warren, J. Y. Takekawa, S. E. W. De la Cruz, and M. Parker. 2014. Relative contribution of lipid sources to eggs of lesser scaup. Journal of Avian Biology 45: 197-201.

Dawson, R. D., and R. G. Clark. 1996. Effects of variation in egg size and hatching date on survival of lesser scaup Aythya affinis ducklings. Ibis 138: 693-699.

DeVink, J-M., R. G. Clark, S. M. Slattery, and T. M. Scheuhammer. 2008a. Effects of dietary selenium on reproduction and body mass of captive lesser scaup. Environmental Toxicology and Chemistry 27: 471-477.

DeVink, J-M., R. G. Clark, S. M. Slattery, and M. Wayland. 2008b. Is selenium affecting body condition and reproduction in boreal breeding scaup, scoters, and ringnecked ducks? Environmental Pollution 152: 116-122.

DeVink, J.-M., R. G. Clark, S. M. Slattery, and D. L. Trauger. 2008c. Are late-spring boreal Lesser Scaup (Aythya affinis) in poor body condition? Auk 125: 291-298.

Diem, K. L., and K. H. Lu. 1960. Factors influencing waterfowl censuses in the parklands, Alberta, Canada. Journal of Wildlife Management 24: 113-133.

Dooley, J., K. Fleming, P. Garrettson, W. Rhodes, and N. Zimpfer. 2015. Waterfowl population status, 2015. United States Department of the Interior, Washington, DC, USA. Accessed 3 December 2015. http://www.fws.gov /migratorybirds/pdf/surveys-and-data/Population-status /WaterfowlPopulationStatusReport.pdf.

Drever, M. C., R. G. Clark, C. Derksen, S. M. Slattery, P. Toose, and T. D. Nudds. 2012. Population vulnerability to climate change linked to timing of breeding in boreal ducks. Global Change Biology 18: 480-492.

Esler, D., J. B. Grand, and A. D. Afton. 2001. Intraspecific variation in nutrient reserve use during clutch formation by lesser scaup. Condor 103: 810-820.

Fournier, M. A., and J. E. Hines. 2001. Breeding ecology of sympatric greater and lesser scaup (Athya marila and Athya affinis) in the subarctic Northwest Territories. Arctic 54: 444-456.

Gallop, J. B., and W. H. Marshall. 1954. A guide for aging duck broods in the field. Technical session report. Mississippi Flyway Council, Louisana Department of Wildlife and Fisheries, Baton Rouge, Louisana, USA.

Gehrman, K. H. 1951. An ecological study of the Lesser Scaup duck (Aythya affinis Eyton) at West Medical Lake, Spokane County Washington. M.Sc. thesis, State College of Washington, Pullman, Washington, USA. 
Gurney, K. E. B., R. G. Clark, S. M. Slattery, N. V. SmithDowney, J. Walker, L. M. Armstrong, S. E. Stephens, M. Petrula, R. M. Corcoran, K. H. Martin, K. A. DeGroot, R. W. Brook, A. D. Afton, K. Cutting, J. M. Warren, M. Fournier, and D. N. Koons. 2011. Time constraints in temperate-breeding species: influence of growing season length on reproductive strategies. Ecography 34: 628-636.

Guyn, K. L., and R. G. Clark. 1999. Decoy trap bias and effects of markers on reproduction of northern pintails. Journal of Field Ornithology 70: 504-513.

Hammell, G. S. 1973. The ecology of the lesser scaup (Aythya affinis Eyton) in southwestern Manitoba. M.Sc. thesis, University of Guelph, Guelph, Ontario, Canada.

Hammell, G. S. 2014. Erickson study area: duck breeding populations and habitat, then (1970-72) and now (2008-13). Bluejay 72: 123-139.

Hines, J. E. 1977. Nesting and brood ecology of Lesser Scaup at Waterhen Marsh, Saskatchewan. Canadian FieldNaturalist 91: 248-255.

Holliday, I. E. 2012. Kolmogorov-Smirnov test (version 1.0.3) in Free Statistics Software (version 1.1.23-r7). Office for Research Development and Education. Accessed 3 January 2015. http://www.wessa.net/rwasp_Reddy-Moores\%20KS\%20Test.wasp/.

Johnson, D. H. 1979. Estimating nest success: the Mayfield method and an alternative. Auk 96: 651-661.

Keith, L. B. 1961. A study of waterfowl ecology on srnall impoundments in southeastern Alberta. Wildlife Monographs 6: 3-88.

Koons, D. N. 2001. Lesser scaup breeding ecology in the Canadian parklands. M.Sc. thesis, Montana State University, Bozeman, Montana, USA.

Koons, D. N., and J. J. Rotella. 2003. Have Lesser Scaup, Aythya affinis, reproductive rates declined in parkland Manitoba? Canadian Field-Naturalist 117: 582-588.

Koons, D. N., J. J. Rotella, D. W. Willey, M. Taper, R. G. Clark, S. Slattery, R. W. Brook, R. M. Corcoran, and J. R. Lovvorn. 2006. Lesser Scaup population dynamics: what can be learned from available data? Avian Conservation and Ecology 1(3): 6 .

Martin, K. H. 2007. Breeding ecology and fasting tolerance of scaup and other ducks in the boreal forest of Alaska. M.Sc. thesis, University of Alaska, Fairbanks, Alaska, USA

Martin, K.H., M. S. Lindberg, J. A. Schmutz, and M. R. Bertram. 2009. Lesser scaup breeding probability and female survival on the Yukon Flats, Alaska. Journal of Wildlife Management 73: 914-923.

Mayfield, H. 1975. Suggestions for calculating nest success. Wilson Bulletin 87: 456- 466.

McDonald, J. H. 2009. Fisher's exact test of independence. In Handbook of Biological Statistics (2nd Edition). Sparky House Publishing, Baltimore, Maryland, USA.

McDonald, J. H. 2014. Kruskal-Wallis test. In Handbook of Biological Statistics (3rd Edition). Sparky House Publishing, Baltimore, Maryland, USA.
Migratory Bird Data Center. n.d. Division of Migratory Bird Management, Waterfowl Breeding Population and Habitat Survey, United States Fish and Wildlife Service. Accessed 3 December 2015. https://migbirdapps.fws.gov/.

Pagano, A. M., and T. W. Arnold. 2007. Detection probabilities for ground-based breeding waterfowl surveys. Journal of Wildlife Management 73: 392-398.

Paquette, G. A., J. H. Devries, R. B. Emery, D. W. Howerter, B. L. Joynt, and T. P. Sankowski. 1997. Effects of transmitters on reproduction and survival of wild mallards. Journal of Wildlife Management 61: 953-961.

Pietz, P. J., D. A. Brandt, G. L. Krapu, and D. A. Buhl. 1995. Modified transmitter attachment method for adult ducks. Journal of Field Ornithology 66: 408-417.

Rogers, J. P. 1962. The ecological effects of drought on reproduction of the Lesser Scaup, Aythya affinis (Eyton). Ph.D. thesis, University of Missouri, Columbia, Missouri, USA.

Rogers, J. P. 1964. Effect of drought on reproduction of the Lesser Scaup. Journal of Wildlife Management 28: 213222.

Smith, A. G. 1971. Ecological factors affecting waterfowl production in the Alberta parklands. Resource Publication 98. United States Fish and Wildlife Service, Washington, DC, USA.

Stewart, R. E., and H. A. Kantrud. 1971. Classification of natural ponds and lakes in the glaciated prairie region. Resource publication 92. United States Fish and Wildlife Service, Washington, DC, USA.

Sugden, L. G., and H. J. Poston. 1968. A nasal marker for ducks. Journal of Wildlife Management 32: 984-986.

Sunde, L. A., and J. Barica. 1975. Geography and lake morphometry of the aquatic study area in the Erickson-Elphinstone district of southwestern Manitoba. Technical report 510. Fisheries and Marine Service, Environment Canada, Winnipeg, Manitoba, Canada.

Trauger, D. L. 1971. Population ecology of lesser scaup (Aythya affinis) in subarctic taiga. Ph.D. thesis, Iowa State University, Ames, Iowa, USA.

Walker, J. A., and M. S. Lindberg. 2005. Survival of scaup ducklings in the boreal forest of Alaska. Journal of Wildlife Management 69: 592-600.

Walker, J. A., M. S. Lindberg, M. C. MacCluskie, M. J. Petrula, and J. S. Sedinger. 2005. Nest survival of scaup and other ducks in the boreal forest of Alaska. Journal of Wildlife Management 69: 582-591.

Warren, J. M., K. A. Cutting, and D. N. Koons. 2013. Body condition dynamics and the cost-of-delay hypothesis in a temperate-breeding duck. Journal of Avian Biology 44: 575-582.

Westerskov, K. 1950. Methods for determining the age of game bird eggs. Journal of Wildlife Management 14: $57-$ 67.

Received 27 May 2015

Accepted 5 February 2016 